\title{
Minor head injury: pathophysiological or iatrogenic sequelae?
}

\author{
Freda Newcombe, P Rabbitt, $M$ Briggs
}

\begin{abstract}
This study addresses the possibility that cognitive sequelae-albeit of a transient or minor character-can be associated with mild head injury. Twenty men (aged 16-30 years of age), whose post-traumatic amnesia did not exceed eight hours, were examined within 48 hours of their accident and again one month later. This unselected sample had no previous history of head injury. A control group of 20 men of similar socioeconomic background, was selected from medical wards (where they had been admitted for orthopaedic treatment or a minor operation). They were also retested one month after the first examination. Neuropsychological tests were selected to measure abilities often compromised after significant head injury, namely memory and attention. The experimental component consisted of the fractionation of a complex skill (paced addition) to probe for deficits at different stages of information processing: perception and input into storage; search for and retrieval of information from working memory; and paced and unpaced addition. In general, no significant difference was found between the experimental and control groups, with the possible exception of an initial decrement on two working memory tasks: probe digits and a keeping track task (where the subject has to keep in mind and update a number of variables at the same time). The keeping track paradigm, ostensibly of ecological relevance, may well be worth further exploration in memory research, and in studies of more severely head-injured patients. It is further suggested that the appropriate management and counselling of mildly head-injured patients may help to avert symptoms that are of psychological rather than pathophysiological origin.
\end{abstract}

$(\mathcal{F}$ Neurol Neurosurg Psychiatry 1994;57:709-716)

The classical taxonomy ${ }^{1}$ of blunt head injury, in terms of the severity of brain damage, is usually defined by the duration of post-traumatic amnesia (PTA). In the absence of readily accessible and appropriate neuroimaging to reflect the massive axonal shearing associated with such injury, ${ }^{2}$ PTA has been considered the best available biological marker of severity of brain damage. Meticulous necropsy data $^{3}$ on patients who died from other causes, however, have indicated diffuse neuronal shearing after (very) minor head injury, and thus implicity widened the field of enquiry. Cases of minor head injury, initially relegated to "the dumping ground of neurasthenia" (Symonds, ${ }^{4}$ p.607), were then entitled to neuropsychological evaluation with the expectation that subtle forms of attentional or memory loss, or both, might be elicited.

The seminal research of Gronwall and coworkers $^{5-7}$ indicated such attentional impairments, at least during the weeks immediately after injury. Neurophysiological changes persisting up to six months after a very mild head injury have also been reported ${ }^{8}$ : large deviations from the normal evoked potential response were recorded in these trauma patients as they worked at vigilance and discrimination tasks.

Nevertheless, there is (as yet) no clear consensus as to the nature and duration of the cognitive sequelae of minor head injury. One large-scale and often quoted study (Rimel et $a l,{ }^{9}$ p.221) suggested "some problems with attention, concentration, memory or judgement in most of the subset of 69 patients evaluated neuropsychologically" about three months after injury. It appears, however, that the large sample (with which this subset of patients was comparable in terms of sex, education, and employment) included a large group of college students, a higher percentage of sporting injuries than is common in other samples, ${ }^{10}$ and a relatively high (35\%) percentage of patients with a blood alcohol level in excess of the Virginian limit $(0.10 \mathrm{~g} / \mathrm{l})$ at the time of injury. Almost one-third gave a history of previous head injury. Hence it is unwise to assume that the reported sequelae are characteristic of the effects of a single head injury, uncomplicated by other factors, in other groups of varied demography.

Significant cognitive changes, however, have been reported ${ }^{11-13}$ - at least on short-term follow up-after relatively minor head injury (variously defined as a PTA of less than one day, absence of coma, or brief admission to hospital). Such changes are difficult to evaluate in the absence of appropriate control procedures.

In contrast, several studies of minor head injury ${ }^{14-17}$ have provided essentially negative evidence, at least with regard to permanent symptoms. Gronwall and Wrightson, ${ }^{6}$ for example, reported recovery of performance on 
a paced addition task (PASAT) 54 days after injury in $75(94 \%)$ of 80 patients who had been briefly concussed. In a study in Belfast, ${ }^{15}$ strengthened by the inclusion of a control group, patients reached at least the control level of performance on a four-choice reaction time task six months after injury, despite their significantly poorer performance after shorter intervals of 24 hours and six weeks. The PTA was less than 24 hours and, for half of the group, less than 15 minutes; "those suffering from alcohol intoxication or any other complicated illnesses were excluded". ${ }^{15}$

Likewise, no significant impairment was found on a variety of cognitive tests (digit cancellation, digit span, verbal memory, word recognition, Buschke's selective reminding paradigm for word recall, card sorting, and Raven's progressive matrices) in a group of 50 Italian patients tested one month after injury. ${ }^{16}$ There were clearly defined criteria for admission to this study: loss of consciousness for less than 20 minutes and an initial score on the Glasgow coma scale ${ }^{18}$ of 13-15. Patients selected their own controls from among family, friends, and schoolmates ("case control pairing").

Similarly, a carefully designed three-centre study in the USA suggested that "a single, uncomplicated minor head injury produces no permanent, disabling neurobehavioural impairment in the great majority of patients free of pre-existing neuropsychiatric disorder and substance abuse" (Levin et al, ${ }^{19}$ p.234). Of the 155 patients initially studied, $57(37 \%)$ returned for a one-month follow up and met the strict criteria for inclusion in the study. These criteria included a Glasgow coma scale score of at least 13, and absence of focal neurological deficit, intracranial mass lesion (haematoma), intracranial surgical procedures (for example, repair of depressed skull fracture), or complications such as meningitis. Other criteria included admission to hospital for 24 hours or less, no general anaesthesia (for example, for an operation related to extracranial injuries), and no history of antecedent neurological disorder, admission to hospital for previous head trauma, sustained alcohol or drug abuse or admission to hospital for psychiatric disorder. The baseline assessment was carried out within seven days of injury when the initial PTA had resolved, and the follow-up examination no later than five weeks after injury. The tests were selected to measure attention, memory, and speed of information processing. The three-centre study strongly supported the view that these rigorously selected patients with minor closed-head injury did not differ from wellmatched controls on tests carefully chosen to probe those skills that are characteristically impaired in more severe closed-head injury. It also provided striking evidence of epidemiological influences: considerable variation between centres with respect to the aetiology of injury and a remarkable difference in the level of performance between centres. On initial testing, the control group was superior to the head-injured group on all five tasks of which the verbal memory test was the most sensitive. This group difference disappeared, however, one month after injury when there was a notable improvement in verbal memory. Post-concussional symptoms-headache, dizziness, and decreased energy-were initially reported by a substantial number of the total patient sample but had decreased at the one-month follow up to 56,35 , and $47 \%$, respectively. These workers note that "patients treated in emergency rooms or hospitalized for minor head injury are typically given minimal or no instructions concerning the risk for development of neurobehavioural sequelae and temporal course, nor are these residual effects adequately evaluated on any systematic basis" and they suggest that "secondary emotional distress leading to aggravation of post-concussional symptoms and excessive time away from work after minor head injury could be mitigated by early clinical intervention..." (Levin et al, ${ }^{19}$ pp.241-3).

Given the controversial nature of the reported research on the sequelae of minor head injury, we decided to test the possibility of subtle deficits in memory, attention, and speed of processing in a group of young men with a PTA of less than one day. The sample was particularly suitable for this exercise. The Oxford accident service admits over 1000 patients with trauma annually; these are direct referrals from a wide catchment area and hence compose an unbiased sample of trauma patients in three counties. A pilot study (cited in Thomas $^{20}$ ) established the main demographic characteristics of the 340 men between the ages of 16 and 55 admitted during a six month period. Road traffic accidents constituted the major cause of trauma (46\%), followed by falls $(16 \%)$, and assaults $(13 \%)$. Over $80 \%$ were estimated to have had PTA of less than one day and over $90 \%$ were discharged within 24-48 hours. Against the background of the national statistics available, ${ }^{10}$ the population provides a reasonable cross section of trauma patients in the UK, without the notorious alcohol intake of a disproportionate number of assault cases to be found in a few metropolitan areas. A subset of subsequent admissions from our regional population was therefore considered eminently suitable for a study of the cognitive sequelae of a first, minor head injury.

In applied research of this nature there are alternative but complementary research strategies. The traditional psychometric approach analyses performance on measures of those cognitive abilities that are consistently reported to be impaired after head injury: namely, memory and attention. ${ }^{21-26}$ Alternatively, a complex task (reportedly sensitive to the effects of closed-head injury) can be fractionated in terms of an information processing model. Predictions can then be made about performance from this model and tested with appropriately designed experimental tasks. In the absence of a solid foundation of prior knowledge about the sequelae of minor head injury, we adopted both approaches. 


\section{Subjects and methods} SUBJECTS

Twenty men between the ages of 16 and 30 years who lived within easy reach of the hospital and who were admitted to the accident service after minor head injury between February and August 1976 were examined. The injuries were due to road traffic accidents; no skull fractures were present. In no patient was there a previous history of head injury and none had physical injuries sufficiently severe to prevent them getting out of bed within the first 48 hours of injury. Estimates of the length of PTA were based on ambulance and clinical notes, interview, and the continuous screening of memory and orientation by the neuropsychologist. The number of patients in the different categories of PTA were as follows: PTA of a few minutes, seven $(35 \%)$; less than half an hour, seven (35\%); less than one hour, three $(15 \%)$; and one to eight hours, three $(15 \%)$. Patients were tested within 48 hours of the accident and again one month later.

Twenty male control patients were selected from the medical wards: nine orthopaedic patients and 11 patients admitted for a minor operation. They were tested within one week of admission and then again at follow up one month after admission.

The two groups did not differ in age or performance on standard verbal and non-verbal tests of intelligence: head-injured group mean (SD) age 21.4 (3.9), matrices score $45 \cdot 7$ (11.1), and Mill Hill IQ equivalent $99 \cdot 3$ (14.7); control subjects mean (SD) age $21 \cdot 2$ years (3.5), matrices score $49.6(6.4)$, and Mill Hill IQ equivalent $105 \cdot 2(12 \cdot 8)$.

\section{TEST PROCEDURE}

The two groups were each tested twice: the experimental group within 24 hours of admission and one month later; the control group on two occasions, initially during hospital admission and, at follow up, one month later.

Owing to medical and administrative exigences, it was, in a few instances, not possible to administer all the tests. In the two groups, however, all but two subjects completed all the tests, with the sole exception of the control test of arithmetical ability which was not administered to three members of the headinjured group.

\section{TEST SELECTION}

\section{Memory and information processing}

Tests of memory and information processing often produce significant differences between patients with severe closed-head injury and normal controls. They were therefore included on the premise that smaller but consistent differences might be detected after less severe injuries. In addition, one verbal memory task-story recall-is known to correlate well with relatives' ratings of the daily life memory ${ }^{25}$ of the head-injured patient. The following tests were administered.

Story recall

Bower's ${ }^{27}$ hierarchical story-frame paradigm was used to test the possibility that the headinjured patients would either be unable to abstract the hierarchy or forget more details at lower levels of the hierarchy. This procedure awards higher scores for recalling general abstract features of the story and lower scores for details-unlike conventional story recall tests in standard test batteries. The story used for the first test session was a shortened version of Circle Island with 194 words and 32 recall items. The (Torrida) story for the second test session was devised to approximate the Circle Island format, with 199 words and 33 recall items. At each session the experimenter read the story aloud and the subject's verbatim response was recorded on tape. Delayed recall, without forwarning, was recorded one hour later. The score was the number of story items recalled correctly.

\section{Word and face recognition}

Verbal and non-verbal continuous recognition tasks, based on the Shepard and Teghtsoonian paradigm, ${ }^{28}$ were designed and included to check the rate of loss of items in immediate memory as a function of the passage of time and intervening interference. Such tasks might therefore detect a factor implicated in the previously reported difficulties with paced addition tasks. ${ }^{6-7}$ Subjects were shown a set of stimuli and told that each stimulus occurred twice in the test pack with varying numbers of other stimuli between the target items. They had to go through the pack and respond "old" if the stimuli had been seen before in the pack and "new" if it had not occurred previously. There were five intervals, with stimuli recurring after one, five, 10,15 , or 20 cards.

In the verbal version of the test, the stimuli consisted of six-letter words typed on individual cards. The 50 target stimuli consisted of 25 high frequency (Thorndike-Lorge AA) and 25 low frequency (Thorndike-Lorge 5/million) words. Five words of each frequency occurred at each interval. Three words which did not recur were included at the end of the pack to keep the probability of new or old stimuli at $50 \%$. There were thus 53 new words which could have been falsely recognised. A brief practice task was given initially to ensure that all the subjects understood the test.

In the non-verbal version of the task, the stimuli consisted of 40 pictures of the faces of young ex-servicemen, with neutral expressions, and without paraphernalia or idiosyncratic hair cut. There were eight target items at each of the five intervals and 44 opportunities for false positive errors.

\section{Prospective memory}

At the end of the first test session each patient was given a form to fill in when he returned to work and a stamped addressed envelope in which to return it to the experimenter. The number of patients who returned the slip and the time elapsing between return to work and return of the slip (the date of the postmark) were taken into account. 


\section{Card sorting}

Sorting tasks were included to provide a comparative measure of the rate of information processing between patients and controls. The subject was given a pack of cards face down and was asked to sort them in labelled red and black piles. For the control measurement of movement time, subjects were given a pack of alternating red and black cards to be sorted into the two piles. In the two-choice condition, they were given a shuffled pack of cards, again to be sorted into red and black piles. This test was repeated three times with the left/right spatial position of the red and black pile alternating on each occasion. Times were averaged. In the four-choice condition, the shuffled pack had again to be sorted into two piles but each pile contained two suits that is, hearts and spades on one side and diamonds and clubs on the other. This test was repeated four times with each of the two combinations of suits occurring twice, each time in an alternate spatial position. Time scores were averaged. At the beginning of each session, packs were checked so that there were never more than three of the same colour and not more than one of the same suit in succession. Between each test, packs were shuffled at least four times. The two-choice and fourchoice conditions were repeated once at the end of the testing programme as a check for possible fatigue effects.

PACED ADDITION TASK AND ITS COMPONENTS The paced addition task $\left(\right.$ PASAT) ${ }^{79} 30$ was the key experimental paradigm, selected on the basis of Gronwell and Sampson's ${ }^{5}$ innovative studies. In this task, subjects hear a stream of single digits. Their task is continuously to add the last digit spoken to the one immediately preceding it. The speed of presentation can be varied. Gronwell and Sampson ${ }^{5}$ ascribed the reduced cognitive efficiency of patients during the first month after mild and moderate concussion (reflected on PASAT, choice reaction time, and speech processing tasks) to "reduced informationprocessing capacity" (p. 84). They eliminated selective attention, response production, and movement time as critical parameters.

In analysing the PASAT task we envisaged three main stages of information processing and the experimental techniques that might be required to test these components.

Perception and input into storage

This component was thoroughly explored and eliminated by Gronwall and Sampson ${ }^{5}$ as a critical parameter.

\section{Search for and retrieval of information from working memory}

In the PASAT task the correct (penultimate) digit must be selected from several items in working memory, and then added to the last digit presented. As a reasonable simulation of this component of PASAT, we chose the probe digit technique. ${ }^{31}$ Here, subjects have to identify items in working memory by their nature (item search).
In addition, the efficiency with which subjects could keep track of information held in working memory was also tested by the Yntema and Mueser paradigm. ${ }^{32}$ The latter task checks the rate of loss of items in immediate memory as a function of the passage of time and intervening interference. It thus investigates a component of PASAT to find out whether the rate of loss of items in memory is also implicated in PASAT failures.

\section{Paced and unpaced addition}

Straightforward control tasks measured performance on the arithmetical component of PASAT when there was no extra demand on resources by a working memory load. The specific tests selected are described in the following.

Modified PASAT-The present version consisted of 51 digits ( 50 pairs of single digits to be added together) relayed on a portable Sony tape recorder at two different speeds: 'slow' (one digit every three seconds) and 'fast' (one digit every 1.5 seconds). Omissions and four types of error were recorded to attempt to check the relative vulnerability to head injury of the various cognitive processes involved in this complex task. Omissions and late errors might indicate breakdowns due to the optimum speed of performance being exceeded. "Retrieval errors" and "addition errors" might indicate inefficient addressing or maintenance of information in working memory. "Miscellaneous errors" represented a catch-all category of failures unattributable to any particular process. Two short control/ practice tasks preceded the administration of PASAT: the successive repetition of 10 digits spoken by the same experimenter and relayed on the same apparatus and the addition of digit pairs, presented at the "slow" rate (one digit every three seconds).

Arithmetical ability test-To check parity on those components of PASAT which involved paced arithmetical ability subjects were asked to add pairs of single digits (e.g. $8+3=$ ?) played on the same tape recorder as the conventional PASAT at the same two speeds. Twenty-five additions were given at the "slow" speed and 50 at the "fast" speed. Incorrect responses were scored as "late responses", "omissions", or "additional errors".

Probe digits test-These tasks checked the ability to retrieve items and item order from working memory. Subjects heard a series of seven random digits relayed on a tape recorder, followed, after a three second gap, by a single digit. There were two conditions. In the item condition, subjects had to say whether the single (probe) digit had occurred in the immediately preceding set of seven digits. Twenty four positive and 24 negative probes were given in pseudo-random order. Digits in each of the six positions (excepting the first) were probed twice. In the order condition, the probe digit had invariably occurred in the preceding series of seven digits. The subject had to name the digit that had immediately preceded the probe. Each of the six positions in the series (excluding the first) was 
tested four times. The conventional scoring system was used.

Keeping track task-This task was based on an interesting paradigm developed by Yntema and Mueser ${ }^{32}$ to assess the subject's ability to keep track of several variables, simultaneously. Ostensibly, it might tap a proverbial difficulty of the head-injured patient in attending to several concurrent strands of conversation. One of the problems in PASAT is that subjects have to select the correct one of several possible digits, correctly referencing items in working memory. The keeping track task was therefore an extended analogue of this aspect of the PASAT task. Subjects have to address items not merely in terms of temporal sequence but also in terms of category (pile).

Patients were asked to sort, face down, a pack of 56 cards into four piles according to category: digits (1-10), letters (A-K, excluding I), colours (colour names written in the appropriate colour in upper case letters), and shapes (heart, diamond, club, spade, circle, square, rectangle, triangle, star and cross, outlined in black ink). There were 10 message cards in each category and the message cards were interspersed with question cards, displaying a $Q$ and the name of the category. Subjects then had to recall as many items from that category as they had previously sorted. The number of cards intervening between the presentation of an item and its subsequent recall varied from none to seven; and there was one item at each interval from both the "verbal" (number and letters) and "non-verbal" (colours and shapes) category. The score was taken as the number of items correctly recalled (maximum 76, 19 from each category). Errors included extraneous items (for example, letters beyond $\mathrm{K}$ in the alphabetic sequence) and visual confusions.

\section{Results}

INITIAL TESTING

Significant group differences were observed only on working memory tasks-keeping track and item digit probe. Other group comparisons were negative.

In the interests of brevity, analyses of variance for specific tasks are summarised in the following.

\section{Memory and information-processing paradigms}

Story recall-There was a significant effect of delay $(F=9.93, \mathrm{p}<0.005)$ for the two groups (see tables 1 and 2). To investigate Bower's ${ }^{32}$ centrality hypothesis, the first and second higher-order levels in the Circle Island story hierarchies were combined and compared with the third and fourth levels. The ANOVA took delays and levels as repeated measures to be computed for each story separately. The effect of levels was significant $(F=37.43, \mathrm{p}<0.005)$ as was the effect of delays $(F=7 \cdot 25, \mathrm{p}<0.01)$, but there was no difference between the two groups. A similar pattern emerged from an analysis of the Torrida story.
Recognition - The data for the verbal version were subjected to a three-way analysis of variance consisting of groups, frequencies, and intervals between successive presentations of the stimulus. The main effects of interval $(F=4.48, \mathrm{p}<0.005)$ and frequency $(F=4.77, \mathrm{p}<0.05)$ were significant, but there was no difference between the groups. In addition, there was no difference between the groups in terms of error pattern (false negative and false positive errors). For the two groups, performance was worse on high frequency words and with longer intervals between successive presentations of the same stimulus.

In the non-verbal (faces) version only the effect of interval was significant $(F=4 \cdot 56$, $\mathrm{p}<0.005$ ) for the two groups.

Prospective memory-The difference between the percentage of head-injured $(60 \%)$ and control $(65 \%)$ patients returning their forms did not differ significantly $\left(\chi^{2}=0.008\right.$, $\mathrm{df}=1)$. The time elapsing between return to work and return of the form did not differ between the two groups (mean 3.5 days), excluding one control patient who brought his form back 10 days before returning to work.

Card sorting - The effect of choice was highly significant $(F=465.21, \mathrm{p}<0.0005)$ : sorting was slower if there were more alternative categories. There was no significant difference between the groups, though the head-injured patients were on average $5.7 \mathrm{sec}-$ onds slower than the control patients and also significantly more variable (tests for homogeneity of variance: movement time $F=2 \cdot 61$, $\mathrm{p}<0.05$; two choice, $F_{\max }=3.27, \mathrm{p}<0.025$; four choice, $\left.F_{\max }=3.40, \mathrm{p}<0.05\right)$.

\section{Paced addition and its components}

Modified PASAT - The main effect of error type was significant $(F=3.36, \mathrm{p}<0.025)$ and there was a significant interaction between error type and speed $(F=6.73, \mathrm{p}<0.0005)$. The two groups made more late responses on the fast speed than on the slow speed and more of the other error types on the slower speed. This interaction cancelled out the main effect of speed.

Paced addition-There was a highly significant effect of speed as a repeated measure $(F=178 \cdot 19, \mathrm{p}<0.001)$ : the two groups performed less well at the faster presentation rate. There was, however, no significant difference between groups nor interaction between groups and presentation rate.

Probe digits - There was a highly significant effect of position $(F=6.70, \mathrm{p}<0.0005)$ in the item condition: performance was best on the last three positions, with fewer items intervening between presentation and recall; it was also relatively good on the first item of the series. The head-injured patients recalled significantly fewer items than the controls $(F=8 \cdot 10, \mathrm{p}<0.005)$. Tables 3 and 4 give these results.

Effect of position in the order condition was highly significant $(F=5 \cdot 76, \mathrm{p}<0.0005)$ : performance was best on the first and last 
Table 1 Keeping track task: mean (SD) percentage recall

\begin{tabular}{lcc}
\hline Task category & $\begin{array}{l}\text { Head-injured } \\
\text { patients }\end{array}$ & $\begin{array}{l}\text { Control } \\
\text { subjects }\end{array}$ \\
\hline Numbers & $36 \cdot 3(25 \cdot 4)$ & $48 \cdot 4(18 \cdot 5)$ \\
Letters & $25 \cdot 0(13 \cdot 6)$ & $38 \cdot 7(20 \cdot 6)$ \\
Shapes & $66 \cdot 3(17 \cdot 4)$ & $69 \cdot 2(11 \cdot 6)$ \\
Colours & $56 \cdot 3(21 \cdot 2)$ & $65 \cdot 8(20 \cdot 8)$ \\
Total & $46 \cdot 0(14 \cdot 1)$ & $55 \cdot 5 \quad(14 \cdot 1)$ \\
Time (s) & $371 \cdot 5(116 \cdot 8)$ & $331 \cdot 1(82 \cdot 2)$ \\
\hline
\end{tabular}

Table 2 Keeping track task: analyses of variance

\begin{tabular}{lrrr}
\hline & \multicolumn{3}{l}{ Source } \\
\cline { 2 - 4 } & $d f$ & \multicolumn{1}{l}{$M S$} & \multicolumn{1}{c}{$F$} \\
\hline Groups & 1 & 131.41 & 9.97 \\
Categories & 3 & 396.31 & 30.06 \\
Groups $\times$ categories & 3 & $8 \cdot 17$ & 0.62 \\
Between subjects within groups & 152 & 13.18 & \\
\hline
\end{tabular}

items of the series. There was, however, no group difference.

Keeping track-The head-injured patients recalled significantly fewer items than the controls and the effect of category was also significant $(F=30.06, \mathrm{p}<0.0005)$ but there was no interaction effect (tables 1 and 2). The head-injured patients differed significantly from the controls on letter $(t=2 \cdot 48, \mathrm{df}=33$, $\mathrm{p}<0.01)$ and number recall $(t=1.72$, $\mathrm{df}=33, \mathrm{p}<0.05)$ as well as on total recall $(t=2.4, \quad \mathrm{df}=33, \mathrm{p}<0.025)$. The two groups, however, reported that the letters and numbers were more difficult to recall than colours and shapes, an effect probably attributable to set size and imageability. The two groups did not differ significantly in sorting speed $(t=1 \cdot 18, \mathrm{df}=33, \mathrm{p}<0 \cdot 25)$.

Table 3 Item probe task: mean (SD) percentage correct

\begin{tabular}{lcc}
\hline Item conditions & $\begin{array}{l}\text { Head-injured } \\
\text { patients }\end{array}$ & Control subjects \\
\hline Position & & \\
2 & $89 \cdot 0(21 \cdot 4)$ & $89 \cdot 5(26 \cdot 8)$ \\
3 & $66 \cdot 5(38 \cdot 3)$ & $84 \cdot 0(40 \cdot 1)$ \\
4 & $72 \cdot 0(31 \cdot 1)$ & $94 \cdot 5(15 \cdot 8)$ \\
5 & $94 \cdot 0(16 \cdot 2)$ & $100 \cdot 0(0 \cdot 0)$ \\
6 & $91 \cdot 5(19 \cdot 2)$ & $94 \cdot 5(15 \cdot 0)$ \\
7 & $100 \cdot 0(0 \cdot 0)$ & $100 \cdot 0(0 \cdot 0)$ \\
Order & & \\
2 & $63 \cdot 8(31 \cdot 2)$ & $75 \cdot 0(27 \cdot 6)$ \\
3 & $45 \cdot 8(31 \cdot 2)$ & $46 \cdot 0(39 \cdot 3)$ \\
4 & $55 \cdot 5(27 \cdot 8)$ & $54 \cdot 0(33 \cdot 6)$ \\
5 & $30 \cdot 5(20 \cdot 3)$ & $51 \cdot 25(34 \cdot 8)$ \\
6 & $47 \cdot 3(28 \cdot 3)$ & $55 \cdot 25(28 \cdot 4)$ \\
7 & $72 \cdot 3(29 \cdot 6)$ & $68 \cdot 5(24 \cdot 8)$ \\
Total & $52 \cdot 8(21 \cdot 3)$ & $58 \cdot 3(24 \cdot 8)$ \\
\hline
\end{tabular}

Table 4 Item probe task: analyses of variance

\begin{tabular}{lrrr}
\hline & \multicolumn{3}{l}{ Source } \\
\cline { 2 - 4 } & $d f$ & $M S$ & $F$ \\
\hline Item condition & 1 & 1.50 & $8 \cdot 10$ \\
$\quad$ Groups & 5 & $1 \cdot 23$ & $6 \cdot 70$ \\
Positions & 5 & $0 \cdot 33$ & $1 \cdot 81$ \\
Groups $\times$ positions & 210 & $0 \cdot 18$ & \\
$\quad$ Between subjects within groups & 1 & 2.97 & 1.97 \\
Order condition & 5 & 8.71 & 5.76 \\
$\quad$ Groups & 5 & 1.29 & 0.85 \\
Positions & 210 & 1.51 & \\
Groups $\times$ positions & & & \\
Between subjects within groups & & &
\end{tabular}

\section{Homogeneity of sample}

On the assumption that the head-injured group might be a heterogenous sample, including a subset of patients who were significantly impaired by the accident, the data were analysed in two ways: a search for consistently poor performance in a subset of patients and a correlation between performance and grade of PTA.

There was no evidence of a subset of patients showing impairment on all tasks. In relation to PTA, only broad categories could be used because of the restricted range and inevitable imprecision of measurement.

Three categories of PTA were taken into consideration: less than five minutes (seven patients), between five and 30 minutes (seven patients), and more than 30 minutes (six patients). No significant relation was found between task performance and duration of PTA within these narrow limits. The subgroup with the longer time of PTA obtained marginally higher scores on the two intelligence tests (though this effect did not reach significance on an analysis of variance).

There was, however, a consistent trend toward increased variability in the headinjured group which reached significance in card sorting.

\section{FOLLOW UP}

Smaller groups of head-injured (14 patients) and control (14 patients) subjects returned for follow up. There was again a significant difference between the two groups on the item condition of the probe digit task $(F=10.95$, $\mathrm{p}<0.005)$. Otherwise, there were few significant changes in the pattern of performance. These consisted of: PASAT (the two groups scored significantly higher on retest, at slow $(F=16.88, \mathrm{p}<0.0005)$, medium $(F=8.03$, $\mathrm{p}<0.025)$, and fast $(F=20.83, \mathrm{p}<0.0005)$ speeds); story recall (the effect of delay was no longer significant-the two groups remembered as much of the story an hour later as they had on immediate recall); and keeping track (there was now no difference in mean score between the two groups).

\section{Discussion}

In an unselected and hence representative sample of patients with minor head injury in the Oxford region, there was no evidence of a significant and overall decrement in performance on cognitive tests within 48 hours of injury compared with that of control subjects. Had there been any substantial cognitive impairment, we would have expected to have elicited it with the tasks selected and within a short time interval after injury. The absence of an overall group difference is perhaps surprising in view of "the clear evidence of cognitive deficits in the first few days after mild head injury", listed by Binder ${ }^{13}$ (p. 327). Our ostensibly negative findings are, however, consistent with the European studies previously cited, including those of Lidvall et al ${ }^{17}$ who found no cognitive impairment in mildly head-injured patients tested two, six, 14, 30, 
and 90 days after injury and also with one of the most thorough and rigorous studies in North America by Levin and colleagues. ${ }^{19}$ Demographic and cultural factors, as well as differences in medicolegal practice, may perhaps play an important part in explaining such reported discrepancies. There are, of course, other factors to be taken into account including the age of the patients: older patients are thought to be "at greater risk for prolonged disability" 13 (p.328). In addition, there are always problems in the selection of appropriate control subjects. In this study the fact that some of the controls had received an anaesthetic (albeit mild and at least 24 hours before testing) might, arguably, have reduced possible experimental and control group differences. The control group did not perform significantly better, however, when retested one month after treatment.

Our inability to replicate Gronwall and Sampson's ${ }^{5}$ findings could be attributed to a number of factors. Major factors were probably the shorter trials and slower pacing rates used. Gronwall's (personal communication) reanalysis of her original data, using only the first $\mathbf{5 0}$ additions, showed that only two of the speed conditions (digits presented at 0.8 and 2.4 second intervals) produced significant differences between the experimental and control groups. There were also procedural and methodological differences between the two studies. Half the subjects in the earlier study received the fast version of PASAT first. Then, in this study, the $3.0 \mathrm{~s}$ trial is slower than any of those used in Gronwall and Sampson's original studies. ${ }^{5}$ Another factor to be taken into account is the length of the examination. In this experiment, the subjects worked continuously for about two hours. It is conceivable that a longer period of testing might have elicited fatigue and reduced levels of competence in the experimental group, but Gronwall reported that when a 4.0 second interval was introduced between digits, headinjured patients were better than controls, though only a small group (six patients) was used and the results were not significant. We note, nevertheless, that Oddy $^{33}$ did not find a difference between groups of controls and young male head-injured patients (selected on the basis of a PTA of more than two days) tested six months after injury. It has also been suggested that the PASAT may be an unreliable task, showing considerable intra-subject differences.

Two aspects of our data, however, suggest caution in disclaiming any significant, even if transitory, effects of minor head injury. First, there was an early decrement on tasks measuring working memory (digit probe and keeping track), and the significant difference on digit probe was found again one month after injury (albeit in small groups due to the $30 \%$ dropout rate in experimental subjects and controls). It could be argued that these few significant differences emerged by chance. In rebuttal, they can be considered to have a certain functional consistency. Thus measurement of three distinct processes-information processing rate, intermediate term memory, and working memory-showed no decrement except for the mild decrease in working memory, at least in the initial examination. Hence we suggest that although it has been very hard to produce convincing evidence of impairment in a number of the well-controlled recent studies, it is possible that selective studies of working memory would tap significant effects.

The possibility of group differences is supported by data from a study parallel with our own by Saan (unpublished data) in which another unselected group of young men with a first, single head injury was compared with other well-matched control subjects. Embedded in a cluster of negative findings (from tasks including writing and tapping speeds, letter and design fluency, letter and dot cancellation, and sentence comprehension) was a significant group difference on another version of the keeping track task. What might have been considered a statistical artefact tends to reinforce the notion of a (probably transient) working memory deficit. We suggest that the keeping track task presents an interesting paradigm that may well tap a typical patient disorder: keeping in mind and updating a number of variables at the same time-perhaps not dissimilar to the proverbial "cocktail party problem" of the aphasic patient.

Secondly, the consistent increase in the variance of the head-injured patients' performance (see tables 3 and 4, a modified sign test on the variance was significant at the level of $\mathrm{p}<0.01$ ) hints at the possibility of individual outliers whose performance is impaired (see also Leininger et $a l^{34}$ ). Again, this finding raises the possibility of subtle, selective effects; variability of performance may be a more sensitive index than rate alone.

Future studies of minor and moderate head injury call for more sophisticated test procedures $^{35} 36$ and more heuristic models of memory and attentional processes ${ }^{37} 38$ than have been available or used in the past. Given that background, and a rigorous definition of patient and control samples, uncontaminated by substance abuse and medicolegal manipulation, we may be better equipped to study the "primary" effects of closed (blunt) head injury. Recent advances in neuroimaging - specifically, the superiority of MRI over CT in reflecting CNS damage after head injury ${ }^{39-43}$ will help increasingly to define the nature and extent of CNS damage in relation to behavioural (cognitive and affective) changes. Sophisticated neuroimaging may also serve as a complementary measure of severity of damage to that of PTA which, as Symonds ${ }^{4}$ (p.606) pointed out over 40 years ago, can be misleading, and is often not systematically measured (but see references 44-46).

The delicate issue of primary symptoms and secondary psychosomatic, emotional, or motivational factors will not be broached in detail (for judicious reviews see references 43 and 44). We will only recapitulate that many patients with closed-head injury are given 
little in the way of positive counselling, ${ }^{47} 48$ despite the reported efficacy of early reassurance and proactive treatment. ${ }^{49} \mathrm{~A}$ careful study by Minderhoud et $a l,{ }^{50}$ which should certainly be replicated, contrasted the recovery from minor head injury of unselected groups of patients: one group was not treated and was not usually given an outpatient follow-up appointment. The experimental group was "treated with strict instructions regarding the period they should remain in bed .... and given as much information and encouragement as was possible in the given circumstances" (p.128). Minderhoud et al reported that post-concussional sequelae were markedly reduced by treatment which included information, explanation, and encouragement. They hypothesised that "post-concussional sequelae start off on an organic basis (PTA) and that persistent sequelae after minor head injuries are also caused by psychogenic, and especially by iatrogenic factors" (p.127). In the management of minor head injury, the clinician has presumably to steer a judicious course between positive counselling for the long term and the detection of selective (usually transient) cognitive impairments in individual patients.

The authors are indebted to Ms Caroline M Thomas for her meticulous collection and analysis of data. The work was supported by MRC Grant No G/973/144 to Dr Freda ported by

1 Russell WR. The traumatic amnesias. London: Oxford University Press, 1971.

2 Teasdale G, Mendelow D. Pathophysiology of head injuries. In: Brooks N, ed. Closed head injury: psychological, social and family consequences. Oxford: Oxford University Press, 1984:4-36.

3 Oppenheimer DR. Microscopic lesions in the brain following head injury. $\mathcal{F}$ Neurol Neurosurg Psychiatry 1968; 31:299-306.

4 Symonds CP. Discussion on differential diagnosis and treatment of post-contusional states. Proc $R$ Soc $M e d$ 1942;35:601-14.

5 Gronwall DMA, Sampson H. The psychological effects of concussion. Auckland: Auckland University Press, 1974.

6 Gronwall D, Wrightson P. Delayed recovery of intellectua function after minor head injury. Lancet 1974;ii:605-9.

7 Gronwall D. Paced auditory serial-addition task: a measure of recovery from concussion. Percept Mot Skills 1977;44:367-73

8 Curry H, Cummins BH. Electrophysiological changes after head injury. Presented at the Seventh Internationa Congress of Neurological Surgery; 1981 Jul 12-18; Munich.

9 Rimel RW, Giordani B, Barth JT, Boll TJ, Jane JA. Disability caused by minor head injury. Neurosurgery 1981;9:221-8.

10 Field JH. Epidemiology of head injuries in England and Wales. London: HMSO, 1976

11 Van Zomeren AH, Deelman BG. Long-term recovery of visual reaction time after closed head injury. $\mathcal{F}$ Neurol Neurosurg Psychiatry 1978;41:452-7.

12 Barth JT, Macciocchi SN, Giordani B, Rimel R, Jane JA, Boll TJ. Neuropsychological sequelae of minor head injury. Neurosurgery 1983;13:529-33.

13 Binder LM. Persisting symptoms after mild head injury: a review of the postconcussive syndrome. $\mathcal{F}$ Clin Exp review of the postconcussive
Neuropsychol $1986 ; 8: 323-46$.

14 McMillan TM, Glucksman EE. The neuropsychology of moderate head injury. $f$ Neurol Neurosurg Psychiatry 1987;50:393-7.

15 MacFlynn G, Montgomery E, Fenton GW, Rutherford W. Measurement of reaction time following minor head injury. $\mathcal{F}$ Neurol Neurosurg Psychiatry 1984;47:1326-31.

16 Gentilini $M$, Nichelli $P$, Schoenhuber $R$, et al. Neuropsychological evaluation of mild head injury. $\dot{f}$ Neurol Neurosurg Psychiatry 1985;48:137-40.

17 Lidvall HF, Lindroth B, Norlin B. Causes of the postcon- cussional syndrome. Acta Neurol Scand Suppl 1974,50.Suppl. 56, 1-144.

18 Teasdale G, Jennett B. Assessment of coma and impaired consciousness. A practical scale. Lancet 1974;ii:81-4.

19 Levin HS, Mattis S, Ruff RM, et al. Neurobehavioura outcome following minor head injury: a three-centre study. F Neurosurg 1987;66:234-43.

20 Thomas CM. Deficits of memory and attention following closed head injury. [unpublished MSc thesis]. Oxford: Oxford Univ, 1977

21 Ruesch J. Intellectual impairment in head injuries. $\mathrm{Am} \mathcal{F}$ Psychiatry 1944;100:480-96.

22 Fodor IE. Impairment of memory function after acute head injury. I Neurol Neurosurg Psychiatry 1972;35: 818-24.

23 Brooks DN. Long and short term memory in head injured patients. Cortex 1975;1:329-40.

24 Brooks DN, ed. Closed head injury: psychological, social and family consequences. Oxford: Oxford University Press,

25 Baddeley A, Sunderland A, Harris J. How well do laboratory-based psychological tests predict patients' performance outside the laboratory? In: Corkin S, Davies KI Growden JH, Usdin E, Wurtman RJH, eds. Alzheimer's disease: a report of progress. Vol 19. New York: Raven Press, 1982;141-8.

26 Deelman BG, Saan RJ, van Zomeren AH. Traumatic brain injury. Clinical, social and rehabilitational aspects. Amsterdam: Swets \& Zeitlinger, 1990.

27 Bower G. Experiments on story understanding and recall. Qf Exp Psychol 1976;28:511-34.

28 Shepard RN, Teghtsoonian M. Retention of information under conditions approaching a steady state. $\mathcal{F} \operatorname{Exp}$ Psychol 1961;62:302-9.

29 Sampson $\mathrm{H}$. Pacing and performance on a serial addition test. Can $\mathcal{f}$ Psychol 1956;10:219-25.

30 Sampson $H$. Stimulus duration and paced performance. Can $\mathcal{F}$ Psychol 1958;12:7-12.

31 Waugh NC, Norman DA. Primary memory. Psychol Rev 1965;72:89-104.

32 Yntema DB, Mueser GE. Remembering the present state of a number of variables. $\mathcal{F}$ Exp Psychol 1960;60:18-22.

33 Oddy MJ. Psychological and social aspects of recover from closed head injury [unpublished $\mathrm{PhD}$ thesis]. London: Univ of London.

34 Leininger BE, Gramling SE, Farrell AD, Kreutzer JS, Peck EA. Neuropsychological deficits in symptomatic minor head injury patients after concussion and mild concussion. F Neurol Neurosurg Psychiatry 1990;53:293-6.

35 Williams DH, Levin HS, Eisenberg HM. Mild head injury classification. Neurosurgery 1990;27:422-8.

36 Hugenholtz H, Stuss DT, Stethem Li, Richard MT. How long does it take to recover from a mild concussion? long does it take to recove
Neurosurgery 1988;22:853-8.

37 Van Zomeren AH, Brouwer WH. Head injury and concepts of attention. In: Levin HS, Grafman J, Eisenberg cepts of attention. In: Levin HS, Grafman J, Eisenberg New York: Oxford, 398-415.

38 Parasuraman R, Mutter SA, Molloy R. Sustained attention following mild closed head injury. $f$ Clin Exp Neuropsychol 1991;13:789-811.

39 Han JS, Kaufman B, Alfidi RJ, et al. Head trauma evaluated by magnetic resonance and computed tomography: a comparison. Radiology 1984;150:71-7.

40 Jenkins A, Teasdale G, Hadley MDM, Macpherson P Rowan JO. Brain lesions detected by magnetic resonance imaging in mild and severe head injuries. Lancet 1986;ii:445-6.

41 Levin HS, Handel SF, Goldman AM, Eisenberg HM Magnetic resonance imaging after 'diffuse' nonmissile head injury. Arch Neurol 1985;42:963-8.

42 Snow RB, Zimmerman RD, Gandy SE, Deck MDF. Comparison of magnetic resonance imaging and computer tomography in the evaluation of head injury. puter tomography in the
Neurosurgery $1986 ; 18: 45-52$.

43 Wilson Wiedman KD, Hadley DM, Condon B Teasdale G, Brooks DN. Early and late magnetic resonance imaging and neuropsychological outcome after head injury. I Neurol Neurosurg Psychiatry 1988;51. 391-6.

44 Artiola I, Fortuny L, Briggs M, Newcombe F, Ratcliff G, Thomas C. Measuring the duration of post-traumatic amnesia. $\mathcal{F}$ Neurol Neurosurg Psychiatry 1980;43:377-9.

45 Levin HS, Benton AL, Grossman RG. Neurobehavioral consequences of head injury. New York: Oxford University Press, 1982.

46 Shores EA, Marosszeky JE, Sandanam J, Batchelor J. Preliminary validation of a clinical scale for measuring the duration of post-traumatic amnesia. Med $\mathcal{f}$ Aust 1986;144:596-72.

47 Kelly $R$. The post-traumatic syndrome: an iatrogenic disease. Forensic Sci 1975;6:17-24.

48 Panting $A$, Merry $P$. The long-term rehabilitation of severe head injuries with particular reference to the need for social and medical report for the patient's family. Rehabilitation 1972;38:33-7.

49 Rosenbaum M, Lipsitz N, Abraham J, Najenson T. A description of an intensive treatment project for the rehabilitation of severely brain-injured soldiers. Scand $\mathcal{f}$ Rehabil 1978;10:1-6.

50 Minderhoud JM, Boelens MEM, Huizenga J, Saan RJ Treatment of minor head injuries. Clin Neurol Neurosurg 1980;82:127-40. 